Autor invitado 


\title{
Enunciación
}

http://revistas.udistrital.edu.co/ojs/index.php/enunc

DOI: http://doi.org/10.14483/22486798.13789

\section{Ser, saber, poder: experimentos en el laboratorio para la vida y la escuela}

\author{
Being, knowledge, power: laboratory experiments for life and school
}

\begin{abstract}
Adrián Perea*
Agradezco la amable invitación que los profesores Sandra Patricia Quitián y Mario Montoya me han hecho para presentar este texto como síntesis propositiva de un conjunto de ideas que sostienen algunas investigaciones, realizadas a lo largo de diez años, en cuatro programas distintos de la Universidad Distrital Francisco José de Caldas: la Licenciatura en Educación Básica con énfasis en Humanidades y Lengua Castellana; la Especialización en Gerencia de Proyectos Educativos Institucionales; la Maestría en Investigación Social Interdisciplinaria, y el Doctorado en Estudios Sociales. La evolución de estas empieza con la pregunta por la relación lenguaje/pensamiento/acción y derivó a la cuestión de la gerencia educativa como modo de gobierno, es decir, como acción política. Tal postulado resultó funcionando como principio de inteligibilidad de la acción pedagógica, término acuñado por el profesor Pedro Baquero, en la pregunta por la formación para la crítica de los docentes del Distrito, investigación Ilevada a cabo conjuntamente entre el Doctorado y el IDEP, en el segundo semestre de 2017.

Aclarado esto, ocupémonos ahora de los cuatro verbos que componen el título de la propuesta. Digo cuatro, porque, aunque se expliciten solo tres: ser, saber, poder; el cuarto está implícito en el sustantivo experimento. Experimentar, en la secuencia discursiva señalada, termina dirigiendo el modo de aproximarnos a los otros tres infinitivos. Es conocido que, en el ámbito de las ciencias, los sustantivos experimento y experimentación se circunscriben al espacio cerrado del laboratorio. En este juego de palabras, el título sugiere la posibilidad de ampliar tal espacio para el experimento a la escuela y a la vida. Las combinaciones, que pueden ser muchas, podrían sistematizarse así:

a. La escuela es un espacio formativo para la vida.

b. La vida es un problema para la escuela.

c. La escuela es un espacio de producción y reproducción del ser, del saber y del poder.

d. Los maestros son los sujetos de esta producción y reproducción cuando se reconocen como agentes políticos y científicos.
\end{abstract}

Asumiendo que la anterior serie arbitraria describiera de alguna manera un conjunto de supuestos fuertes acerca del papel de los docentes en la escuela como espacio que problematiza la vida, una pregunta a considerar sería: ¿Cómo podría un experimentar sobre el ser, el saber y el poder de los maestros servir como herramienta analítica y propositiva de su acción pedagógica y política? Tal problematización emerge

* Docente de la Universidad Distrital Francisco José de Caldas (Colombia). Adscrito al Doctorado en Estudios Sociales. Doctor en Filosofía por la Pontificia Universidad Javeriana (Colombia). Correo electrónico: samuraiaj@gmail.com - ORCID: https://orcid.org/0000-0002-1832-9838

Cómo citar este artículo: Perea, A. (2018). Ser, saber, poder: experimentos en el laboratorio para la vida y la escuela. Enunciación, 23(2), 238-242. DOI: http://doi. org/10.14483/22486798.13789 
cuando consideramos que ocuparse de la vida en la escuela implica necesariamente la vida del docente, sobre todo en la relación con los infinitivos considerados aquí. Un maestro es un modo de ser específico (no todos son maestros), y es un ser que debe saber como parte constitutiva de su ser maestro, pues no es maestro quien no sabe, lo que lo ubica en una relación de poder, en un espacio privilegiado de acción política, no solo por su posible rol de autoridad, sino especialmente por el conjunto de obligaciones que esta sociedad le impone en el orden de la formación de ciudadanos. La subjetividad del maestro, es decir, cómo alguien se relaciona consigo mismo en la búsqueda de ser maestro, involucraría entonces un entramado complejo entre estos verbos, susceptible de expresarse como se detalla en la tabla 1.

La generalidad del anterior cuadro permite presentarlo como un espacio abierto, en el que pueden proliferar muchas preguntas más. Sin embargo, en la apuesta realizada por las investigaciones señaladas anteriormente, se propone un conjunto de interconexiones entre los tres infinitivos iniciales (tabla 2).

Sin embargo, hace falta considerar el cuarto infinitivo. Para hacerlo, recurrimos al famoso aforismo 324 de La Gaya Ciencia (Nietzsche, 2014, p. 847):

Tabla 1. Interacciones aspecto/relación

\begin{tabular}{cl}
\hline Aspecto & \multicolumn{1}{c}{ Relación } \\
\hline Ontología & $\begin{array}{l}\text { La especificidad del ser maestro. ¿Qué diferencia a quien es } \\
\text { maestro de quien no? }\end{array}$ \\
\hline Epistemología & $\begin{array}{l}\text { Un maestro es un agente productor y reproductor del saber y } \\
\text { de la cultura. ¿En qué consiste el saber de ser maestro? }\end{array}$ \\
\hline Ética & $\begin{array}{l}\text { En la búsqueda de ser maestro un sujeto realiza operaciones } \\
\text { sobre sí mismo para llegar a serlo. ¿Cómo se ocupa de sí } \\
\text { mismo alguien que quiere ser maestro? }\end{array}$ \\
\hline Política & $\begin{array}{l}\text { Un maestro es, en cuanto tal, un agente político al que se le } \\
\text { encarga la formación de ciudadanos. ¿A qué obligaciones } \\
\text { políticas se sujeta el maestro en la especificidad de su ser } \\
\text { maestro? }\end{array}$ \\
\hline
\end{tabular}

Fuente: elaboración propia.

Tabla 2. Interconexiones relación/expresión

\begin{tabular}{ll}
\hline Relación & \multicolumn{1}{c}{ Expresión } \\
\hline Ser/saber & $\begin{array}{l}\text { Un conjunto de saberes moldea lo que somos. Siempre será po- } \\
\text { sible indagar acerca del papel de ciertos saberes en la configu- } \\
\text { ración de lo que somos. Entre estos, adquiere especial relevan- } \\
\text { cia la pedagogía y sus interacciones con la psicología, etc. }\end{array}$ \\
\hline Ser/poder & $\begin{array}{l}\text { Un conjunto de relaciones de poder delimita nuestra acción } \\
\text { posible. Es el caso de los límites de la acción impuestos en el } \\
\text { dispositivo escolar con fines formativos de muchos órdenes: } \\
\text { productivo, ciudadano, etc. }\end{array}$ \\
\hline Poder/saber & $\begin{array}{l}\text { Tales límites usan como variable estratégica en su construc- } \\
\text { ción modalidades de saber. La especificidad de los límites del } \\
\text { dispositivo se conecta con la especificidad del uso estratégico } \\
\text { de estos saberes en un momento determinado con una finali- } \\
\text { dad precisa. }\end{array}$ \\
\hline
\end{tabular}

Fuente: elaboración propia. 
In media vita.-¡No! ¡La vida no me ha decepcionado! Por el contrario, de año en año la encuentro más verdadera, más deseable, y más misteriosa,-desde aquel día en que descendió sobre mí el gran liberador, el pensamiento de que la vida podría ser un experimento del hombre de conocimiento,-iy no un deber, no una fatalidad, no un engaño! Y el conocimiento mismo: puede que para otros sea algo diferente, por ejemplo, un lecho o el camino hacia un lecho, o un entretenimiento, o una actividad de ocio, para mí es un mundo de peligros y victorias en el que los sentimientos heroicos también tienen sus sitios para danzar y luchar. "La vida un medio del conocimiento"; con este principio en el corazón no sólo se puede vivir valerosamente, sino incluso jvivir alegremente y reír alegremente! ¿Y quién sabría reír y vivir bien si previamente no hubiera sabido de guerra y de victoria?

Aunque este texto es susceptible de muchísimos usos, quedémonos con la afirmación fuerte que propone: la vida podría ser un experimento de aquel que vive. La redundancia se hace necesaria, porque vivir implica esa repetición: se vive, pero se vive una vida, en toda la extensión del término. Una encarnación específica de la vida en la que ahora puede emerger la posibilidad de experimentar con ella como modo de vivirla. Los criterios usados en la tabla 1 permitirían comprender ahora las relaciones entre los cuatro infinitivos (tabla 3).

Tabla 3. Interacciones relación/expresión en los cuatro infinitivos.

\begin{tabular}{|c|c|}
\hline Relación & Expresión \\
\hline Experimentar/ser & $\begin{array}{l}\text { Ontología/Ética. La persecución de un modo de ser es suscep- } \\
\text { tible de realizarse como experimentación vital. La expresión } \\
\text { nietzscheana Llega a ser el que eres explicita tal posibilidad. }\end{array}$ \\
\hline Experimentar/saber & $\begin{array}{l}\text { Epistemología/Ética. El saber ser del ser maestro puede cons- } \\
\text { truirse asumiéndolo como producto no solo de la reproduc- } \\
\text { ción de la cultura, sino especialmente de su crítica, como } \\
\text { ejercicio que impulsaría un saber experimentar ser maestro. }\end{array}$ \\
\hline Experimentar/poder & $\begin{array}{l}\text { Epistemología/política. El maestro como agente político puede } \\
\text { experimentar relaciones de poder que emergerían de los } \\
\text { modos distintos de ser maestro y de saber ser maestro. En estas } \\
\text { aparecen nuevos límites de la acción política y pedagógica. }\end{array}$ \\
\hline
\end{tabular}

Fuente: elaboración propia.

Al visibilizar tales dicotomías, entre los cuatro infinitivos (ser, saber, poder, experimentar) y las cuatro categorías (ontología, epistemología, ética y política) se establecen las condiciones para proponer ahora tres principios en los que toma forma la apuesta de las investigaciones de las que se ha hablado. Estos principios son: formarse para formar, criticar para crear e investigar para educar. Para entrever cómo se interconectan con lo anterior, presentamos un análisis de dichos principios a partir de estos criterios:

\section{Primer principio: formarse para formar}

a. Ontología. El sí mismo es una materia plástica moldeada, por una parte, por dispositivos, en los que se incluyen los educativos, pero también por prácticas reflexivas. Conforme a lo anterior, ser maestro implica configurar un modo específico de ser que se ocupa de sí mismo como condición para ocuparse del otro. Este movimiento reflexivo es específico de la ontología del ser maestro. Ningún otro ser realiza tal práctica reflexiva. Lo que la convierte en condición ontológica del ser maestro. 
b. Epistemología. Formarse implica un conjunto de saberes disponibles en la cultura, sin los cuales no sería posible tal reflexividad. Estos saberes participan en el moldeado de la forma de ser del maestro, son parte de su formación, pero la condición ontológica subordina el aspecto epistemológico de estos saberes, pues es esa actitud, ese deseo de ser, el que está antes de su contacto con esos saberes.

c. Ética. Esta actitud, deseo o movimiento reflexivo es una práctica que el maestro opera sobre sí mismo como condición de su modo de ser maestro, en la que se modifica constantemente y a través de la cual deviene lo que quiere ser. La actividad reflexiva del formarse implica un tomarse a sí mismo como objeto de un trabajo propio que no solo es condición ontológica y epistemológica, sino además ética, en tanto la especificidad de su ser y su saber es la de formar ciudadanos.

d. Política. Tal formación ciudadana significa que el maestro se hace responsable de su formación como punto de partida para comprender su papel como agente político y social, pues no se forma solo con propósitos de ser, sino especialmente para poder ser quien puede, para poder formar a aquellos que deben poder.

\section{Segundo principio: criticar para crear}

a. Ontología. Ser maestro implica ser necesariamente un ser crítico, un ser específicamente crítico. La formación de ciudadanos supone que quien los forma es capaz de criticar para reproducir y crear las ofertas críticas de la cultura. No es maestro quien trabaja para mantener las cosas como están, lo es quien pone en tela de juicio a la cultura en la que vive como objetivo de su tarea existencial.

b. Epistemología. Dado que toda crítica es sobre algo y desde cierto saber, así como nunca se hace en abstracto ni en un espacio aséptico de intereses; se hace necesario que el maestro sepa para que pueda criticar y, desde ahí, sea maestro. Cuestionar los modos como sabe ser maestro también es parte de su trabajo crítico.

c. Ética. La crítica es condición para hacer emerger otros modos de ser. Cuando nos cuestionamos cómo terminamos siendo esto que somos, estos maestros que somos hoy, podemos impulsar investigaciones de muchos órdenes que servirían de insumo y punto de partida para relacionarnos de otro modo con nosotros mismos, es decir, para crear nuevas prácticas reflexivas. También se critica para crear un nuevo modo de ser maestro.

d. Política. La apuesta política del Estado Social de Derecho, consagrado por la Constitución y la ley, al respecto de la educación en Colombia, es por la autonomía y la crítica. Es decir, esta sociedad le abroga al maestro la responsabilidad, compartida con otras instituciones, de formar sujetos capaces de enfrentar la pregunta por sus modos de vivir y de relacionarse con otros en el marco social. Para esto, el maestro debe saber que puede alterar condiciones y límites políticos desde su trabajo crítico como parte de su modo de ser maestro, como condición política para formación de ciudadanos críticos y autónomos.

\section{Tercer principio: investigar para educar}

a. Ontología. Siempre será posible distinguir entre formación y educación en los discursos pedagógicos, pues no se trata de la misma interacción entre ética y epistemología en los dos casos. La clave está en que el maestro es necesariamente un investigador, es decir, alguien que cuestiona su 
cotidianidad y su acción pedagógica desde criterios ofrecidos por los saberes que tiene a la mano o los que ha inventado por experimentación.

b. Epistemología. Los saberes que tiene el maestro le permiten proponer un análisis desde criterios precisos de su entorno y de su acción pedagógica;, convirtiéndose entonces en un productor de un saber ser maestro.

c. Ética. Las relaciones de sí consigo en cuanto maestro se han condensado por milenios en discursos de diversa índole que el maestro puede tener en cuenta a la hora de preguntarse por las prácticas reflexivas que le permiten ser maestro. La investigación que aquí se propone no se refiere solo al contexto y al aula, espacios privilegiados de la acción pedagógica, sino de la reflexividad del agente político que es el maestro, en otras palabras, en el espacio de su subjetividad.

d. Política. La investigación es entonces obligación para el maestro como agente político en los distintos espacios mencionados. Debe aclararse que la efectividad de la agencia dependerá del ejercicio de investigación, especialmente en el carácter crítico del modo de ser maestro, pues unos saberes sirven como herramienta estratégica para cuestionar los límites actuales de nuestros sistemas de gobierno, para preguntarnos por la especificidad de unos nuevos.

Las generalidades presentadas en este análisis inicial de las relaciones entre los infinitivos, los criterios y los principios, esbozan pretende explicitar una apuesta de investigación que se desarrolla hoy en un conjunto de trabajos en el Doctorado en Estudios Sociales. Esta apuesta no es solo por la configuración de un programa de investigación; también lo es por el diseño de herramientas analíticas y propositivas capaces de enfrentar problemas epistemológicos y políticos que emergen en la actualidad, los cuales son objeto de publicaciones disponibles en sus distintos canales comunicativos, y en los que se hacen visibles experimentaciones en el ser, saber y poder de maestros y de otros actores sociales. La invitación a quien lee este texto es a usar esta sistematización inicial como insumo para multiplicar, para hacer proliferar investigaciones y experimentaciones posibles, que sirvan como herramienta estratégica para crear alternativas eficaces a la compleja interacción entre capitalismo y democracia que dirige hoy nuestras vidas. Confiamos en que su ejercicio crítico de esta propuesta sirva como punto de partida para inventar unas nuevas.

\section{Referencia bibliográfica}

Nietzsche, F. (2014). Obras completas IV. Madrid: Editorial Tecnos. 